\title{
Analysis of an Inspection Process Allowing Consecutive Two-time Testing of Products Using Markov Chains
}

\author{
Jeonghan $\mathrm{Ko}^{1^{*}}$ \\ ${ }^{1}$ Department of Industrial Engineering, Ajou University \\ 연속되는 이중 검사를 허용하는 제품품질검사 프로세스에 대한 \\ 마르코프 체인을 이용한 분석 \\ 고정한 ${ }^{*}$ \\ ${ }^{1}$ 아주대학교 산업공학과
}

\begin{abstract}
When a quality inspection process rejects a product unit, consecutive repeated inspections are sometimes conducted for the rejected unit to reduce a false reject possibility. This paper analyzes a special inspection process that allows up to two times of consecutive testing for each product to decrease type I inspection errors. This study uses a Markov chain to model the steps of the inspection process and a product unit's quality states during inspection. Historical inspection results from a company are used as the data for the Markov chain model. Using the Markov chain model and data, this study analyzes the effect of this special inspection rule on the proportion of the final quality levels and scrap rate. The results demonstrate that this inspection process of possible double testing could help reduce unnecessary rejects and consequently decrease material and production costs.
\end{abstract}

요 약 산업현장에서는 품질검사 과정 중의 잘못된 불량판정을 감소시키기 위하여, 각 제품단위에 대하여 불량판정 이 나왔을 경우 복수의 검사를 반복하여 수행하는 경우가 있다. 본 논문은 총 두 번까지의 연속된 검사를 허용하는 품질검사 프로세스에 대한 분석을 다루고 있다. 본 논문에서는 제품검사의 단계와 품질판정 상태를 모델링하는 수학 적 도구로서 마르코프 체인이 사용되었다. 그리고 산업체의 생산관리 시스템에서 수집된 불량 판정률을 마르코프 체 인 모델의 데이터로 사용하였다. 또한 본 논문은 제품의 품질 특성 별 최종 비율과 제품의 폐기율에 대한 이러한 연 속적인 이중검사 허용 프로세스의 영향에 대하여 분석을 수행하였다. 분석 결과, 연속이중검사 허용이 정상 제품에 대한 불량판정을 줄이며, 그 결과 재료, 노동 및 기타 비용을 줄이는 데 기여할 수 있다는 것을 확인하였다.

Key Words : Inspection, two-time testing, quality, type I error, Markov chain

\section{Introduction}

The inspection process is one of the most important steps to assure product quality. The inspection process is especially critical for some electronic components, because the malfunction of a component may lead to not only performance degradation of large systems but also serious safety issues such as fire or accidents. Therefore, electronics manufacturers have developed a variety of inspection processes suitable for their products. In order to evaluate the effectiveness of such inspection processes, it is desirable to conduct quantitative analysis.

This study addresses a special inspection problem in a company that produces electronic products. This

*Corresponding Author: Jeonghan Ko

Tel: +82-31-219-2335 email: jko@ajou.ac.kr

Received May 4, 2012

Revised May 17, 2012

Accepted June 7, 2012 
inspection process is performed because a relatively high reject rate is expected due to sensitive component assembly processes.

In particular, the company would like to evaluate a special inspection policy that allows consecutive repeated testing one more time for a product unit when the product unit has been rejected in the inspection process. The purpose of this repeated testing of up to total two times is to reduce false rejects (type I inspection errors) during inspection and save related costs.

Therefore, the objectives of this study are to (1) model the inspection process that allows up to two times of testing, (2) analyze the resulting quality characteristics and scrap rate from adopting this inspection policy, and (3) evaluate the effectiveness of this inspection process compared to another policy. This study uses a Markov chain (MC) to model and analyze this unique inspection process.

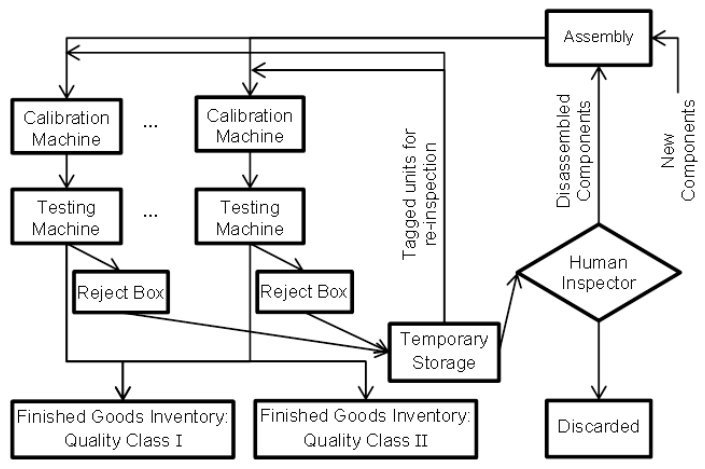

[Fig. 1] Description of the inspection process and its material flows

The inspection process is shown in Figure 1, and described as follows. After the assembly of the components, the products arrive at the calibration-testing station. The calibration and testing station includes a set of machines used for adjusting the electrical signal levels in the products. Then, each product unit is transferred to a testing machine that is directly linked to a calibration machine. If a product unit passes the test in a test machine, the unit is sent to the finished goods inventory for shipping and classified as the first quality class. If a product unit is rejected by the test, it is tagged as a possible bad quality product and manually fed to the calibration and testing process again. This second round test is performed to reduce Type I inspection errors (false rejects). If a product unit passes this second round test, it is sent to the finished goods inventory for the second quality class. If a unit does not pass the second round test, the unit is sent to a human inspector to determine whether or not it should be scrapped or sent for rework (disassembly to components and reassembly of them). Note this description has been modified a little not to reveal the identity of the company and its products.

The merit of this study is to enable a quantitative analysis of this special inspection process so that the quality-related cost can be improved. This study can be used to estimate the cost incurred by the second round inspection as well as scrap and rework. These cost estimates can be used to evaluate different calibrationinspection policies in the company. These evaluations will be used to save costs in terms of labor, scrap, floor space and equipment, and find a proper trade-off among these.

\section{Literature Review}

Markov chains (MC) and Markov decision processes (MDP) have been used to model a variety of quality, production and inspection problems. Markov processes can be used to model complex systems [1], and have often been used for reliability analysis [2]. For instance, a MC was used for the analysis of repairable systems [3-4].

Markov processes have also been used for modeling production systems. The number of units with defects in a multi-stage production line was analyzed by an MDP [5]. An inspection decision in a batch production system was also analyzed by a Markov process [6]. Markov processes were also used for optimal maintenance policies [7-8].

Markov chains are also often used to analyze inspection processes. False rejects of conforming parts (type I errors) and false acceptance of non-conforming ones (type II errors) were analyzed [9]. The effect of inspection on the Work-In-Process (WIP) level was also modeled using an MDP [10].

Markov models have also been used in other variety of areas other than reliability or inspection. For instance, MC 
models were used to analyze the performance of a Wireless Broadband system [11], and to recognize the boundary of biological name entities [12].

\section{Mathematical Definition of the Inspection System}

\subsection{Assumptions}

For the modeling, the following assumptions are necessary. First, after re-assembly, a product unit is as good as a new one in terms of quality. This is reasonable for this product, because the individual components are extremely reliable but the product quality is heavily dependent on the highly variable manual assembly processes. This condition allows the application of the Markov property in this study.

Second, there are no type II errors due to the simple electrical signal characteristics used in the calibration and inspection processes. Each product unit cannot withstand a signal level beyond a threshold if the unit has a quality problem.

\subsection{Markov chain model}

The calibration and inspection system shown in Figure 1 is modeled as a Markov chain (MC). The MC has the states shown in Figure 2. The state transition in the MC is also shown in Figure 2.

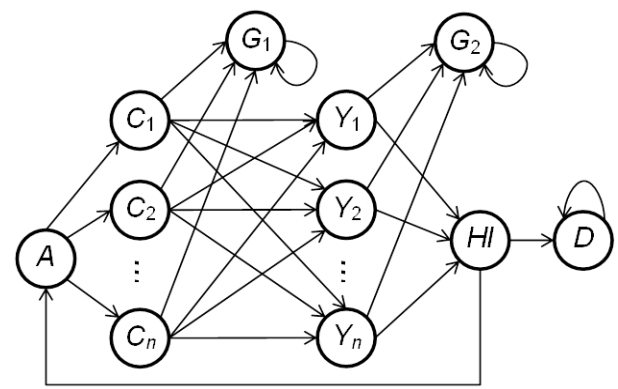

[Fig. 2] State transition diagram of the Markov chain

State $A$ represents that a product unit has not yet entered the inspection process. Physically it represents the assembly stations and storage buffer before the inspection process. The units stay in State $A$ before the calibration process.
The transition from State $A$ occurs to State $C_{i}, i=1$, $\cdots, n$. These states represent that a product unit is in one of the $n$ number of calibration-testing machines and is being calibrated for the first time. Note, because the testing is conducted in the adjacent testing machine immediately after the calibration, each pair of calibration and testing processes is considered as a single MC state. Although a unit passes through two physical processes (calibration and testing), the physical differentiation does not matter in terms of the state definition and transition.

From one of States $C_{1}, \cdots, C_{n}$, two transition types are possible. First, if a unit passes the test, it is sent to the first finished goods inventory. State $G_{1}$ represents that a unit is in the finished goods inventory for the first class quality. $G_{1}$ is an absorbing MC state. Second, if a unit does not pass the test first time, it is tagged and collected, and then calibrated and tested again in one of the $n$ calibration-testing machines. If a unit is in this second time calibration and testing process, it is in state $Y_{i}, i=$ $1, \cdots, n$. Note although a unit in $Y_{i}$ and that in $C_{i}$ are in the physically same machine, these units have different number of calibration and test processes passed.

From one of States $Y_{1}, \cdots, Y_{n}$, two transitions types are possible. If a unit passes the second round calibration and testing process, it goes to another finished goods inventory for low quality products (second class quality). The state transition occurs to $G_{2}$. If a unit does not pass the second round test, it is sent to a human inspector for further analysis. State $H I$ represents that a unit is with a human inspector.

From State $H I$, two transition types are also possible. First, a unit can be discarded because of too much damage during the assembly and testing processes. The discarded units stay in State $D$, which is an absorbing MC state. Second, a unit can be sent to the assembly line again after disassembly. In this case, the MC transits to State $A$.

Please note the differences between the material flows in the physical layout and station transition structure in the $\mathrm{MC}$.

\section{Analysis of the Inspection System}

\subsection{Evaluation of the state transition probability}


[Table 1] The values of the $\mathrm{P}$ matrix used for the numerical example

\begin{tabular}{c|ccccccccccccc} 
& $A$ & $C_{1}$ & $C_{2}$ & $C_{3}$ & $C_{4}$ & $Y_{1}$ & $Y_{2}$ & $Y_{3}$ & $Y_{4}$ & $H I$ & $D$ & $G_{1}$ & $G_{2}$ \\
\hline$A$ & 0 & 0.25 & 0.25 & 0.25 & 0.25 & 0 & 0 & 0 & 0 & 0 & 0 & 0 & 0 \\
$C_{1}$ & 0 & 0 & 0 & 0 & 0 & 0.05 & 0.05 & 0.05 & 0.05 & 0 & 0 & 0.8 & 0 \\
$C_{2}$ & 0 & 0 & 0 & 0 & 0 & 0.05 & 0.05 & 0.05 & 0.05 & 0 & 0 & 0.8 & 0 \\
$C_{3}$ & 0 & 0 & 0 & 0 & 0 & 0.05 & 0.05 & 0.05 & 0.05 & 0 & 0 & 0.8 & 0 \\
$C_{4}$ & 0 & 0 & 0 & 0 & 0 & 0.05 & 0.05 & 0.05 & 0.05 & 0 & 0 & 0.8 & 0 \\
$Y_{1}$ & 0 & 0 & 0 & 0 & 0 & 0 & 0 & 0 & 0 & 0.9 & 0 & 0 & 0.1 \\
$Y_{2}$ & 0 & 0 & 0 & 0 & 0 & 0 & 0 & 0 & 0 & 0.9 & 0 & 0 & 0.1 \\
$Y_{3}$ & 0 & 0 & 0 & 0 & 0 & 0 & 0 & 0 & 0 & 0.9 & 0 & 0 & 0.1 \\
$Y_{4}$ & 0 & 0 & 0 & 0 & 0 & 0 & 0 & 0 & 0 & 0.9 & 0 & 0 & 0.1 \\
$H I$ & 0.1 & 0 & 0 & 0 & 0 & 0 & 0 & 0 & 0 & 0 & 0.9 & 0 & 0 \\
$D$ & 0 & 0 & 0 & 0 & 0 & 0 & 0 & 0 & 0 & 0 & 1 & 0 & 0 \\
$G_{1}$ & 0 & 0 & 0 & 0 & 0 & 0 & 0 & 0 & 0 & 0 & 0 & 1 & 0 \\
$G_{2}$ & 0 & 0 & 0 & 0 & 0 & 0 & 0 & 0 & 0 & 0 & 0 & 0 & 1
\end{tabular}

The transition probability matrix ( $\mathrm{P}$ matrix) is calculated using the collected data. The data were collected from the company's Enterprise Resource Planning (ERP) system, which had records for four calibration-testing machine sets for a two-month [13]. Note, in order not to disclose any sensitive information in the company, the numbers were simplified a little arbitrarily. For instance, the probabilities of being assigned to each calibration machine are set the same in the numerical example in this section, although they vary depending on each machine's characteristics or worker skill levels. Such value of the P matrix is shown in Table 1. In fact, these same values allow the reduction of MC states, but this special case is not included to show a more general case of this MC model.

The $\mathrm{P}$ matrix is re-arranged and divided into four sub-matrices by the state types: transient and absorbing states. The sub-matrix representing the state transition between transient states is denoted as Q matrix and the sub-matrix representing the transition from transient to absorbing states is denoted as $\mathrm{R}$ matrix [14]. The $\mathrm{Q}$ and $\mathrm{R}$ matrices for the previous $\mathrm{P}$ matrix are not shown for the brevity of the writing.

\subsection{Analysis of the portion of the final product-quality classes}

The expected portion of the product units in each quality class can be calculated using the MC analysis. The product units will be classified into three categories by quality. These three are first class good quality, second class good quality and reject quality, and are represented by the units in the three absorbing states $G_{1}, G_{2}$ and $D$, respectively. The probability that the MC would lead to each of the absorbing states can be calculated by the matrix calculation [14]:

$$
\begin{aligned}
& S=(I-Q)^{-1} \\
& F=S \cdot R
\end{aligned}
$$

The calculated value of $\mathrm{F}$ is shown in Table 2. The first row in the matrix $\mathrm{F}$ represents how much portion of the assembled products (including reworked ones) would end up in one of the three states. The probability being absorbed to State $D$ is $16.5 \%$, that to $G_{1}$ is $81.5 \%$, and $G_{2} 2.0 \%$. Note the probability leading to $D$ is lower than $20 \%$, the reject rate in the first calibration-testing. With adoption of the two-time testing policy, the proportion of the finally rejected products was decreased by around $(0.2$ $-0.165) / 0.2=18 \%$. This means that the second round calibration-testing and inspection saves some products 
units from being discarded by Type I inspection errors. Also note that $G_{1}$ probability is also higher than the first round acceptance probability $80 \%$ due to the reworked units.

The above numbers demonstrate the effect of the second round calibration-testing on the increase in the finally accepted units. The increase by $3.5 \%$ of the total units accepted implies potentially large savings in materials and assembly costs.

\subsection{Workload analysis for the human inspector}

The amount of the workload of the human inspector can be evaluated by counting how many units pass through the additional inspection station by the operator. This is calculated by the expected number of visits to State $H I$. This number is calculated using equation (1), and taking the corresponding value of the entry $(A, H I)$ in the $\mathrm{S}$ matrix. The value is 0.18 per unit with the current data. The whole matrix values are not shown for the brevity of the writing.

This number is a little high. On average $18 \%$ of the assembled or reassembled units are inspected by the human operator. This is mainly due to the high failure rates in the second and first round calibration-testing processes. The units that fail in the first round mostly fail again in the second round.

[Table 2] Calculated F matrix values

\begin{tabular}{c|ccc} 
& $D$ & $G_{1}$ & $G_{2}$ \\
\hline$A$ & 0.165 & 0.815 & 0.020 \\
$C_{1}$ & 0.165 & 0.815 & 0.020 \\
$C_{2}$ & 0.165 & 0.815 & 0.020 \\
$C_{3}$ & 0.165 & 0.815 & 0.020 \\
$C_{4}$ & 0.165 & 0.815 & 0.020 \\
$Y_{1}$ & 0.825 & 0.073 & 0.102 \\
$Y_{2}$ & 0.825 & 0.073 & 0.102 \\
$Y_{3}$ & 0.825 & 0.073 & 0.102 \\
$Y_{4}$ & 0.825 & 0.073 & 0.102 \\
$H I$ & 0.916 & 0.081 & 0.002
\end{tabular}

\subsection{Comparison with an inspection policy without the second round testing}

Considering the high re-failure rate in the second round test, it is worth considering removing the second round calibration-testing process. Because the majority fails in the second round testing anyway, the effectiveness of the second round testing can be questioned. The removal of the second round testing means that a rejected unit goes directly to the human inspector.

This inspection policy without the second testing chance is equivalent to removing states $Y_{1}, \cdots, Y_{n}$ and $G_{2}$ in the MC. Thus, the new MC will have a simpler structure, and the analysis will be simpler too. Therefore, only the final numbers are given below in this section without showing detailed calculation.

The new results show that the discarded units increase from $16.5 \%$ to $18.4 \%$. The workload of the human inspector has increased from $18 \%$ of the total units to $20 \%$ (obviously the same as the failure rate). The removal of the second round inspection would save costs by reducing operation and labor costs for the calibrationtesting and total cycle time as well. The workers do not need to sort rejected/tagged units for recalibration and retesting and manually feed them to the machines. However, The removal of the second round inspection would increase the workload of the human inspector as well as the number of (falsely) rejected products.

\section{Conclusions}

This study addressed a special inspection problem in which an additional consecutive repeated testing is allowed when a product unit has been rejected. This study

1) Successfully modeled an inspection policy allowing a two-time testing of a rejected electronic product using Markov chains.

2) Analyzed the number of products in each quality class resulted from this inspection policy.

3) Demonstrated that a Markov chain could be used to model this inspection process with possible re-testing.

The analysis of the results showed that allowing the second round testing had a significant impact on the product acceptance rate. By allowing the two-time testing, the proportion of the finally rejected products was decreased by $18 \%$ compared to the case without the policy. 
In a future study, the model in this paper can be extended to incorporate more detailed cost information to evaluate trade-offs among different inspection policies and their layouts.

\section{Acknowledgement}

This study was motivated by an industrial problem related to a class project supervised by the author at a university. The author thanks the students who brought this industrial case from their company so that the author was able to propose the model. The author also thanks Ehsan Nazarian who reviewed the initial manuscript and helped collect part of the related literature.

\section{References}

[1] Tomek, L., Mainkar, V., Geist, R. M., \& Trivedi, K. S., "Reliability modeling of life-critical, real-time systems", Proceedings of the IEEE, 82(1), pp. 108-121, 1994.

[2] Sang, H., Wang, G., \& Zhou, Z., "Evolutionary multi-objective optimization of inspection frequencies for substation condition-based maintenance", 2011 6th International Forum on Strategic Technology (IFOST), pp. 480-486, 2011.

[3] Zhang, Z., \& Love, C., "A simple recursive Markov chain model to determine the optimal replacement policies under general repairs", Computers \& Operations Research, 27(4), pp. 321-333, 2000.

[4] Bukowski, J. V., "Modeling and analyzing the effects of periodic inspection on the performance of safety-critical systems", IEEE Transactions on Reliability, 50(3), pp. 321-329, 2001

[5] Klein, M., "Markovian decision models for reject allowance problems", Management Science, 12(5), pp. 349-358, 1966.

[6] Finkelshtein, A., Herer, Y. T., Raz, T., \& Ben-Gal, I., "Economic optimization of off-line inspection in a process subject to failure and recovery", IIE Transactions, 37(11), pp. 995-1009, 2005.

[7] Chen, D., Cao, Y., Trivedi, K. S., \& Hong, Y., "Preventive maintenance of multi-state system with phase-type failure time distribution and non-zero inspection time," International Journal of Reliability
Quality and Safety Engineering, 10, pp. 323-344, 2003.

[8] Faddoul, R., Raphael, W., \& Chateauneuf, A., "A generalised partially observable Markov decision process updated by decision trees for maintenance optimisation", Structure and Infrastructure Engineering, 7(10), pp. 783-796, 2011.

[9] Wang, C. H., \& Sheu, S., "Determining the optimal production-maintenance policy with inspection errors: using a Markov chain", Computers \& Operations Research, 30(1), pp. 1-17, 2003.

[10] Borrero, J., \& Akhavan-Tabatabaei, R., "A Markov decision process model for optimal policy making in the maintenance of a single-machine single-product toolset", Proceedings of the 2010 Winter Simulation Conference (WSC), pp. 2594-2605, 2010.

[11] Park, W. \& Kim, H., "Performance analysis using Markov chain in WiBro", Journal of the Korea Academia-Industrial Cooperation Society, 11(1), pp. 190-197, 2010.

[12] Lim, H., "Named entity boundary recognition using hidden Markov model and hierarchical information", Journal of the Korea Academia-Industrial Cooperation Society, 7(2), pp. 182-187, 2006.

[13] Undisclosed company data, "Term project I for IMSE 428”, 2008.

[14] Winston, W. L., Introduction to Probability Models: Operations Research, Volume II, Duxbury Press, 4th edition, 2003.

\section{Jeonghan Ko}

[Regular member]

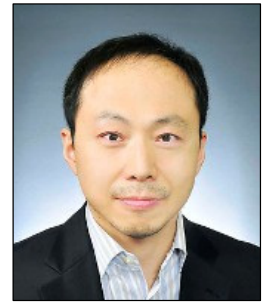

- Dec. 2004 : Univ. of Michigan, Industrial and Operations Engineering, MS

- Aug. 2006 : Univ. of Michigan, Mechanical Engineering, $\mathrm{PhD}$

- Aug. $2007 \sim$ current : Univ. of Nebraska-Lincoln, USA, Dept. of Industrial and Management Systems Engineering, Professor

- Mar. $2012 \sim$ current : Ajou Univ., Dept. of Industrial Engineering, Professor

$<$ Research Interests $>$

Manufacturing systems, Supply chains, Assembly, Quality, Energy systems, Ergonomics in assembly, Applied Operations Research 